\title{
ANALYSIS OF BIOLOGICAL ACTIVITY AND GAS CHROMATOGRAPHY-MASS SPECTROMETRY STUDY OF CONVENTIONAL EXTRACTION OF VITEX NEGUNDO LINN. LEAVES
}

\author{
SAMREEN FATEMA ${ }^{1}$, MILIND UBALE ${ }^{2}$, MAZAHAR FAROOQUI $^{3}$, PATHAN MOHD ARIF ${ }^{1 *}$
}

${ }^{1}$ Department of Chemistry, Maulana Azad College, Aurangabad, Maharashtra, India. ${ }^{2}$ Department of Chemistry, Vasantrao Naik College, Aurangabad, Maharashtra, India. ${ }^{3}$ Department of Chemistry, Dr. Rafiq Zakaria College for Women, Navkhanda, Aurangabad, Maharashtra, India. Email: arif7172@rediffmail.com

Received: 09 June 2018, Revised and Accepted: 27 October 2018

ABSTRACT

Objective: The main objective of the present work is to carry out the biological activity, gas chromatography-mass spectrometry (GC-MS) studies for the possible compounds present in Vitex negundo.

Methods: The aqueous extract of V. negundo Linn. was screened for biological activities such as antimicrobial, antituberculosis (TB), antimalarial, and antioxidant activities. The GC-MS analysis was carried out.

Results: The result shows that leaf extract is effective against Escherichia Coli and Bacillus subtitus while negative results for anti-TB and anti-malarial activity. The antioxidant activity of the leave extract is excellent.

Conclusion: The compounds present in the leaf extract of $V$. negundo are responsible for possessing the biological activity

Keywords: Vitex negundo, Antioxidant activity, Gas chromatography-mass spectrometry study, Aqueous extraction.

(C) 2019 The Authors. Published by Innovare Academic Sciences Pvt Ltd. This is an open access article under the CC BY license (http://creativecommons. org/licenses/by/4. 0/) DOI: http://dx.doi.org/10.22159/ajpcr.2019.v12i12.27854

\section{INTRODUCTION}

Vitex negundo Linn (Synonym: Vitex incise Linn, Vitex incise Lam varhetropylla family: Verbenaceae) is commonly known as nirgudi in India. [1]. Roots, fruits, flowers, leaves, and bark of $V$. negundo have great medicinal value and used for insect repellent purpose $[2,3]$. The leaves of $V$. negundo burned to repel mosquitoes from houses [4]. The leaf extract of $V$. negundo has anticancerous activity [5], it is also used in the treatment of dengue, rheumatism, dyspepsia, diarrhea [6], anti-inflammatory, antimicrobial, antifungal [7], wound healing potential [8,9], analgesic, antifertility [10], antioxidant, and antihyperglycemic activities [11]. Adnaik et al. [12] reported the laxative activity of the aqueous extract of $V$. negundo leaves. Antitumor activity was proved by Dewade et al. [13]. Phytoconstituents play an important role for many activities in a plant. Thombre et al [14] reported the phytoconstituents present in the $V$. negundo and also reported the presence of alkaloids, tannins, steroids, triterpenoids, saponin, protein, and reducing sugars from the ethanol, methanol, acetone, and aqueous extract of $V$. negundo from Pune region.

From the literature survey, it shows the medicinal importance of $V$. negundo Linn. from the different regions of the world. That is why we select the $V$. negundo Linn. plant leaves to give the evidence of some of activities from the Aurangabad region.

\section{METHODS}

The leaf sample of the plant was collected from Vasantrao Naik College Campus, Aurangabad. The plant is identified as V. negundo Linn. and index in herbarium Dr. Bamu. The leaves were washed properly and dried under shade for 6 days. The dried leaves were grind using kitchen grinder to fine powder.

\section{Water extraction}

Accurately weight $30 \mathrm{~g}$ of sample was introduced into the $500 \mathrm{ml}$ round bottom flask (which was first clean by very dilute hydrochloric acid and then distilled water) with $300 \mathrm{ml}$ double-distilled water. The sample was refluxed on flame for $6 \mathrm{~h}$. The sample was cooled and filtered. The excessive water was evaporated for the preservation of the sample, and it was kept at $4^{\circ} \mathrm{C}$ for $12 \mathrm{~h}$.

\section{Antioxidant property}

Antioxidant properties of the samples were measured by 2, 2-diphenyl picrylhydrazyl (DPPH) method [15]. It is very stable free radical commercially available. DPPH reacts with antioxidant molecules present in the herbal extract and converts into diphenyl hydrazine. The intensity was measured at $517 \mathrm{~nm}$. The different concentrations of the extract were prepared. To that $1 \mathrm{ml}$ of extract, $1 \mathrm{ml}$ of DPPH and $3 \mathrm{ml}$ of ethanol were added. Moreover, the intensity of the color was measured at $517 \mathrm{~nm}$. The DPPH radical scavenging capacity was calculated as the percentage inhibition.

$\%$ Inhibition of DPPH radical $=\frac{\text { Control }- \text { Test }}{\text { Control }} \times 100$

Antimicrobial study

With the help of sterile wire loop, the test was inoculated into a test tube containing Mueller Hinton broth. The optical density of the inoculums was adjusted in between 0.08 and 0.1. As per the composition, Mueller Hinton Agar was prepared using sterile distilled water and was sterilized at $121^{\circ} \mathrm{C}$ at $15 \mathrm{lb}$ pressure for $15 \mathrm{~min}$ in an autoclave. The medium was cooled at room temperature and poured in sterile Petri plates and was allowed to solidify. Bacterial inoculums were swabbed over the medium using sterile cotton swab. Sterile disc was placed on medium, on which $20 \mu \mathrm{l}$ of complex suspension was added. Zone of inhibition was observed and measured after incubation at $30^{\circ} \mathrm{C}$ for $18-20 \mathrm{~h}$.

Gas chromatography-mass spectrometry (GC-MS)

The GC-MS analysis of the plant extract was made in a QP 2010 Plus SHIMADZU instrument under computer control at $70 \mathrm{eV}$. About $1 \mu \mathrm{L}$ of the water extract was injected into the GC-MS using a microsyringe and 
scanning was done for $45 \mathrm{~min}$, in which helium is used as the carrier gas. As the compounds were separated, they eluted from the column and entered a detector which was capable of creating an electronic signal whenever the compound was detected. The greater the concentration in the sample, bigger was the signal obtained which was then processed by the computer. The time from when the injection was made (initial time) to when elution occurred is referred to as the retention time (RT). When the instrument was run, the computer-generated graph from the signal called a chromatogram [16].

\section{RESULTS AND DISCUSSION}

In the present study, V. negundo Linn. leaves were tested for the analysis of antioxidant property and antimicrobial study with the standard protocol.

\section{Evaluation of antioxidant activity}

In a healthy person, natural oxidative defence system continuously balanced the production of free radicals [17]. Butylated hydroxy toluene and butylated hydroxyl anisole are the examples of synthetic antioxidants, which need to be replaced by natural antioxidants. Because they found to be toxic and carcinogenic in animal models [18]. The plants are a source of certain bioactive molecule which act as antioxidants. There are so many procedures to determine the antioxidant activity such as DPPH, ABTS, and FRAP [19]. Gupta et al. [20] reported that phytoconstituents are responsible for the antioxidant property of Terminalia bellirica Roxb. ethanolic extract.

In the present study, DPPH method is used to determine the antioxidant activity of $V$. negundo Linn. extract which results as the \% inhibition of

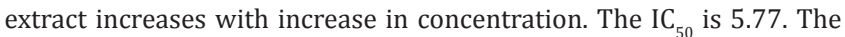
result is shown in Table 1 . The $\mathrm{IC}_{50}$ value of standard ascorbic acid was found to be 14.97, whereas the plant extract shows the $\mathrm{IC}_{50}$ as 5.77. The low value of $\mathrm{IC}_{50}$ indicates that plant extract has more potent antioxidant activity. The percentage inhibition in both ascorbic acid and plant extracts increases linearly with concentration.

\section{Antimicrobial study}

The extract of $V$. negundo Linn. leaves was active against Escherichia coli and Bacillus subtilis bacteria and inactive against Salmonella typhi and Staphylococcus aureus. It does not give any positive result about tuberculosis (TB) and Malaria. It does not show activity against TB and malarial parasites. It may be due the decomposition of the molecule due the continues heat (Table 2).

\section{GC-MS}

Amala and Jeyraj [21] showed the possible compounds present in triphala by GC-MS analysis. 22 peaks are observed in GC-MS study of $V$. negundo Linn. leaf extract. Four peaks are having large \% area (Table 3). Library search at respective RT is shown in Table 4. It is clear that these peaks are for the phytoconstituents present in the plant which are responsible to possess many activities [22]. In the present study, there are four major peaks observed at 13.365, 15.179, 15.264, and 15.458 RT (Fig. 1)

The present study proved that hydro extract of $V$. negundo Linn. possesses good antioxidant property. This may be due to the presence of that n-hexadecanoicacidandhexadecanoicacid, ethyl ester.9,12-octadecodienoic

Table 1: Antioxidant activity of Vitex negundo Linn. leaf extract

\begin{tabular}{llll}
\hline S. No. & Concentration $(\boldsymbol{\mu g} / \mathbf{m l})$ & $\begin{array}{l}\text { \% Inhibition } \\
\text { ascorbic acid }\end{array}$ & $\begin{array}{l}\text { \% Inhibition } \\
\text { extract }\end{array}$ \\
\hline 1. & 5 & 40.48 & 49.33 \\
2. & 10 & 45.09 & 53.81 \\
3. & 20 & 55.15 & 54.06 \\
4. & 30 & 59.39 & 54.66 \\
5. & 40 & 67.15 & 56.72 \\
6. & 50 & 68.00 & 60.24 \\
IC50 value $(\mu \mathrm{g} / \mathrm{ml})$ & 14.97 & 05.77 \\
\hline
\end{tabular}

V. negundo: Vitex negundo acid (Z,Z) shows anti-inflammatory, hypocholesterolemic, cancer preventive, hepatoprotective, and anti-coronary activity [23]. Pentadecanoic acid14-methyl, methyl ester shows antifungal and antimicrobial activity [24]. 9,12,15-octadecatrienoic acid, methyl ester shows the activity against several bacteria [25] such as E. coli and B. subtilis.

\section{CONCLUSION}

The plant extract of $V$. negundo Linn. possesses excellent antioxidant activity and antimicrobial activity against $E$. coli and $B$. subtilis. It shows negative results as anti-TB and antimalarial agents. The GC-MS chromatogram gives 22 peaks at different RTs. The library search reveals the presence of hexadecanoic acid methyl ester, pentadecanoic acid 14-methyl-methyl ester, heptadecanoic acid methyl ester, 9,12-octadecadienoic acid, methyl ester, octadecadienoic acid, methyl ester, 11,14-eicosadienoic acid, 9,12,15-octadecatrienoic acid, methyl ester, 11,14,17-eicosatrienoic acid, methyl ester, 9,12,15-octadecatrien-1-ol, (Z,Z,Z), nonadecanoic acid, methyl ester, hexadecanoic acid, 15-methyl, methyl ester, heptadecanoic acid, 16-methyl, and methyl ester.

\section{ACKNOWLEDGMENT}

We are thankful to Dr. Narayan Pandure, Assistant Professor, Department of Botany, Dr. Babasaheb Ambedkar Marathwada University for his kind support and fruitful discussion. Authors of this article do not have any conflicts of interest with any person, agency, or department.

Table 2: Biological activity of $V$. negundo Linn. leaf extract

\begin{tabular}{lll}
\hline S. No. & Activity & Result \\
\hline 1. & E. coli & Highly active \\
2. & B. subtilis & Active \\
3. & S. typhi & Inactive \\
4. & S. aureus & Inactive \\
5. & TB & -- \\
6. & Malaria & -- \\
\hline
\end{tabular}

E. coli: Escherichia coli, B. subtilis: Bacillus subtilis, Salmonella typhi: Salmonella typhi, S. aureus: Staphylococcus aureus, V. negundo Linn.: Vitex negundo Linn., TB: Tuberculosis

Table 3: Retention time and the peak area of the leaves of V. negundo plant by GC-MS

\begin{tabular}{|c|c|c|}
\hline S. No. & Retention time & Peak area $(\%)$ \\
\hline 1. & 8.046 & 1.13 \\
\hline 2. & 8.967 & 1.89 \\
\hline 3. & 9.680 & 1.64 \\
\hline 4. & 10.091 & 1.21 \\
\hline 5. & 10.746 & 1.26 \\
\hline 6. & 11.362 & 0.22 \\
\hline 7. & 12.444 & 2.12 \\
\hline 8. & 12891 & 1.36 \\
\hline 9. & 13.303 & 3.10 \\
\hline 10. & 13.365 & 20.10 \\
\hline 11. & 13.766 & 0.36 \\
\hline 12. & 14.196 & 0.47 \\
\hline 13. & 14.438 & 0.53 \\
\hline 14. & 15.179 & 7.16 \\
\hline 15. & 15.264 & 30.57 \\
\hline 16. & 15.367 & 2.70 \\
\hline 17. & 15.458 & 9.18 \\
\hline 18. & 15.649 & 1.53 \\
\hline 19. & 16.264 & 2.44 \\
\hline 20. & 17.249 & 2.33 \\
\hline 21. & 17.689 & 0.77 \\
\hline 22. & 18.104 & 1.32 \\
\hline
\end{tabular}

V. negundo Linn.: Vitex negundo Linn., GC-MS: Gas chromatography-mass spectrometry 
Table 4: Possible compounds present in extract as per of GC-MS analysis

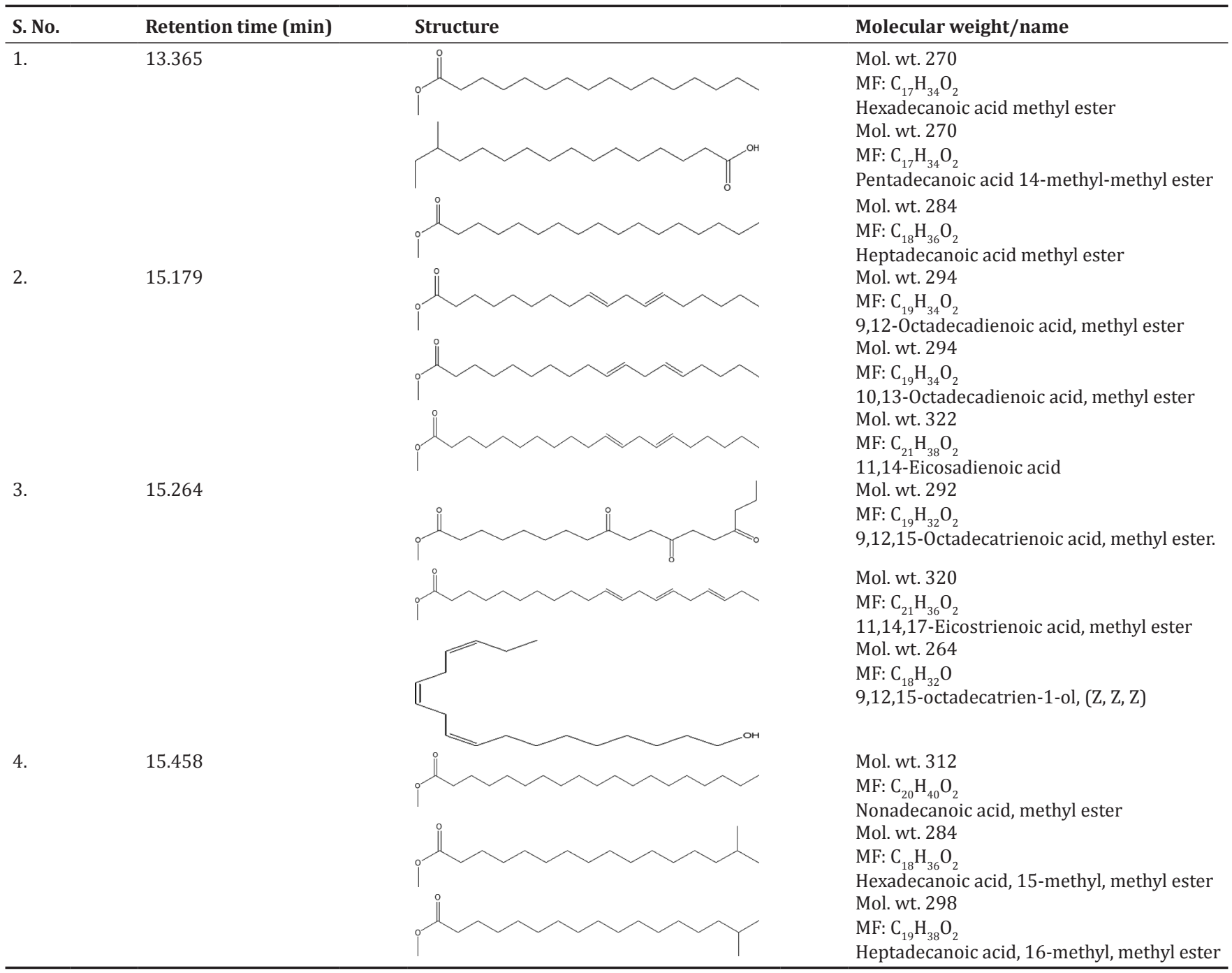

GC-MS: Gas chromatography-mass spectrometry

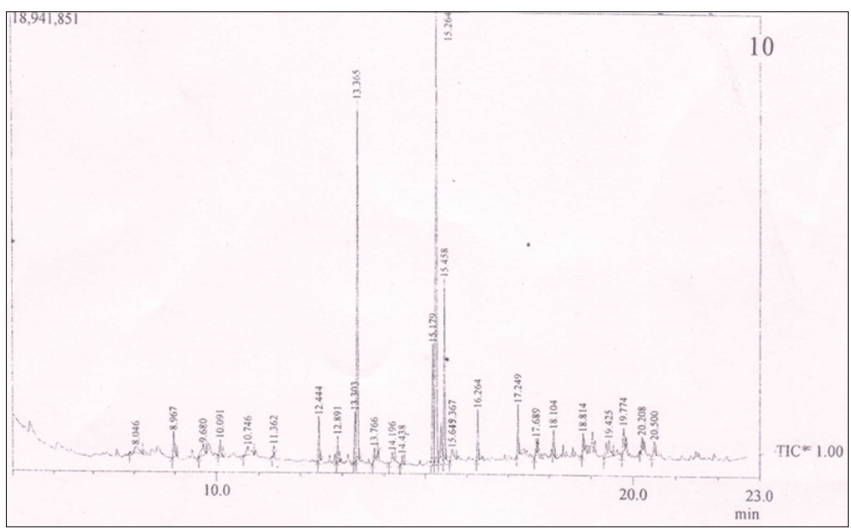

Fig. 1: Gas chromatography-mass spectrometry chromatogram of Vitex negundo aqueous extract

\section{AUTHORS' CONTRIBUTIONS}

Samreen Fatema Research Scholar has majorly performed the experiments in the laboratory. Milind Ubale has provided GC-MS facility and interpretation of data. Mazahar Farooqui has provided help in preparing manuscript, refining, and proofreading of the manuscript and discussion regarding experiment process. Pathan Mohd Arif is research guide and provided the design and content protocol for conducting experiment.

\section{CONFLICTS OF INTEREST}

The authors declare that there are no conflicts of interest regarding the publication of this article.

\section{Graphical abstract}

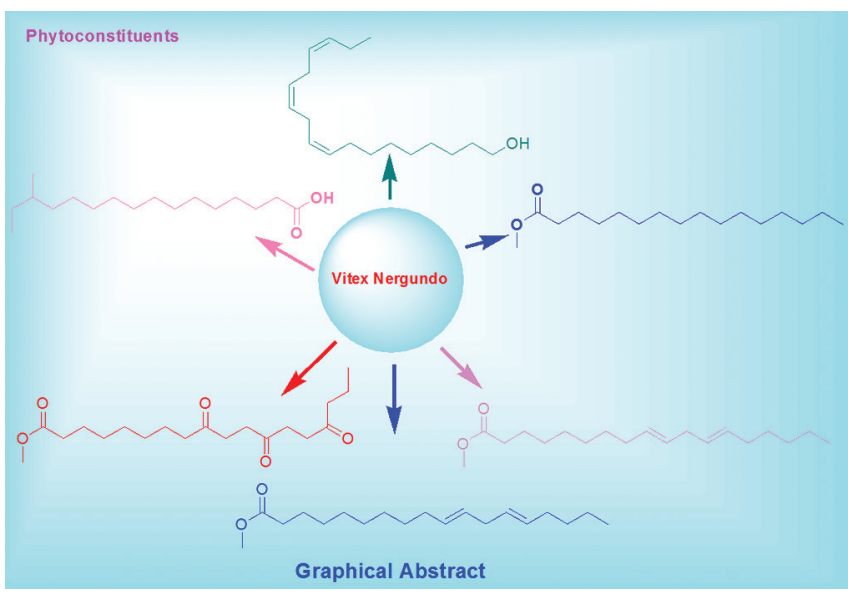

\section{REFERENCES}

1. Murthy JR, Venkataraman S, MeeraKiran R, Deshmukh S, Chidambaraathan N, Devi P. Phytochemical investigation and antipyretic 
activity of leaf extract of Vitex negundo linn. Int J Pharmtech Res 2010;2:1068-73.

2. Mohanraj S, Vanathi P, Barniy NS, Saravaman D. Antimicrobial effectiveness of Vitex negundo leaf extracts. Indian J Fiber Text Res 2012;37:389-92

3. Kannathasan K, Senthilkumar A, Venkatesalu V, Chandrasekaran M. Larvicidal activity of fatty acid methyl esters of Vitex species against Culex quinquefasciatus. Parasitol Res 2008;103:999-1001.

4. Karunamoorthi K, Ramanujam S, Rathinasamy R. Evaluation of leaf extracts of Vitex negundo L. (Family: Verbenaceae) against larvae of Culex tritaeniorhynchus and repellent activity on adult vector mosquitoes. Parasitol Res 2008;103:545-50.

5. Vadawate AV, Barve DM, Dave AM. In vitro flowering and rapid propagation of Vitex negundo L. - A medicinal plant. Indian J Biotechnol 2006;5:112-6

6. Jeyaseelan EC, Pathmanathan MK, Jeyadeven JP. Inhibitory effect of different solvent extracts of Vitex negundo L. and Allium L. on phytopathogenic bacteria. Scholar Res Libr 2011;3:1-8.

7. Aswar PB, Khadabadi SS, Kuchekar BS, Rajukar RM, Saboo SS, Javarkar RD. In vitro evaluation of antibacterial and anti-fungal activity of Vitex negundo (Verbenacceae). Technobotanical Leaf 2009;13:962-7.

8. Talekar YP, Das B, Paul T, Talekar DY, Apte KG. Wound healing potential of Vitex negundo linn in experimental animals. Int $\mathrm{J}$ Pharm Pharm Sci 2012;4: 543-6.

9. Roosewelt C, Vincent S, Sujith K, Darwin CR. Wound healing activity of methanolic extract of Vitex negundo leaves in albino wistar rats. J Pharm Res 2011;4:2553-5.

10. Sharma A, Tyagi S, Nag R, Chaturvedi A, Nag TN. Antimicrobial activity and cellular toxicity of flavonoids extracts from Pongamia pinnata and Vitex negundo. Rom Biotechnol Lett 2011;16:6397-400.

11. Chowdhury FB, Azam FM, Hassan M, Jahan FI, Choedhury AR, Seraj S, et al. Studies with callus induction of Vitex negundo: As an aromatic medicinal plant. Am Eurasian J Sustain Agric 2011;5:6-14.

12. Adnaik RS, Pai PT, Mule SN, Naikwade NS, Magdum CS. Laxative activity of Vitex negundo linn leaves. Asian J Exp Sci 2008;22:159-60.

13. Dewade DR, Christina AJ, Chidambaranathan N, Bhaipale NS, Tekade NP. Antitumor activity of Vitex negundo linnagainst Dalton's Ascitic Lymphoma. Int J Phaemtech Res 2010;2:1101-4.
14. Thombre R, Jagtap R, Patil N. Evaluation of phytoconstituents, antibacterial, antioxidant and cytotoxic activity of Vitex negundo 1 and Tabernaemontana divaricata 1 . Int J Pharm Biosci 2013;4:389-96.

15. Fatema S, Farooqui M, Permila G, Arif PM. The phytochemical and antioxidant property of ethereal extract of Hibiscus rosa-sinensis leaves extract. Res J Pharm Biol Chem Sci 2018;9:603-8.

16. Altameme HJ, Hameed IH, Abu-Serag NA. Analysis of bioactive phytochemical compounds of two medicinal plants, Equisetum arvense and Alchemila valgaris seeds using gas chromatography-mass spectrometry and fourier-transform infrared spectroscopy. Malays Appl Boil 2015;44:47-58.

17. Barreira JC, Ferreeira IC, Oliveira BP, Pereira JA. Antioxidant activities of the extracts from chestnut flower, leaf, skins and fruit. Food Chem 2008; 107:1106-13

18. Hua-Bin L, Ka-Wing C, Chi-Chu W, King-Wai F, Chen F, Jiang Y. Evaluation of antioxidant capacity and total phenolic content of different fractions of selected microalgae. Food Chem 2007;102:771-6.

19. Kardong D, Upadhyaya S, Saikia LR. Screening of phytochemicals, antioxidant and antibacterial activity of crude extract of Pteridium aquilinum kuhn. J Pharm Res 2013;6:179-82.

20. Gupta R, Singh RL, Dwivedi N. In vitro antioxidant activity and GC-MS analysis of the ethanolic extract of Terminelia bellirica roxb (Baheda). Int J Pharm Pharm Sci 2016;8:275-82.

21. Amala VE, Jeyraj M. Determination of antibacterial, antifungal, bioactive constituents of triphala by FT-IR and GC-MS analysis. Int J Pharm Pharm Sci 2014;6:123-6.

22. Praveen Kumar P, Kumaravel S, Lalitha C. Screening of antioxidant activity, total phenolics and GC-MS study of Vitex negundo. Afr J Biochem Res 2010;4:191-5.

23. Hema R, Kumaravel S, Alagundaram K. GC/MS determination of bioactive components of Murraya Koenigii. J Am Sci 2011;7:80-3.

24. Akpuaka A, Ekwenchi MM, Dashak DA, Dildar A. Biological activities of characterized isolated of n-hexane extract of Azadirachta indica a juss (Neem) leaves. Nat Sci 2013;11:119-24.

25. Kalaivani CS, Sathish SS, Jankiraman N, Johnson M. GC-MS studies on Andrographis paniculata (burm. F.) wall ex. Nees - A medicinally important plant. Int J Med Aromat Plants 2012;2:69-74. 